\title{
Exploring the Creative Industries: Toward a Classification by Process and Job Functions
}

\author{
Mirjam M. Koehorst \\ m.m.koehorst@utwente.nl | Faculty of Behavioral, Management and Social Sciences, Department of \\ Communication Science, University of Twente, Drienerlolaan 5, 7522 NB Enschede, The Netherlands \\ Alexander J.A.M. van Deursen \\ a.j.a.m.vandeursen@utwente.nl | Faculty of Behavioral, Management and Social Sciences, Department \\ of Communication Science, University of Twente \\ Jan A.G.M. van Dijk \\ Jan.vanDijk@utwente.nl | Faculty of Behavioral, Management and Social Sciences, Department of \\ Communication Science, University of Twente \\ Jos De Haan \\ j.de.haan@scp.nl | Netherlands Institute for Social Research
}

\begin{abstract}
In Europe, the creative industries (CIs) are experiencing growth rates well above the average of the EU's total economic growth. However, a lack of consensus regarding how these industries work impedes the development of effective policy. In our research, we suggest a process approach to characterize the CIs. This characterization is more flexible in comparison to existing definitions. This process model can be used to easily identify job functions that are important for the development of innovative and creative products or services. Twenty-three semi-structured interviews were conducted with key players in the CIs in the Netherlands. After analysis of these interviews, a process model was developed that consists of the following six steps: (1) problem analysis, (2) concept generation, (3) provisional design, (4) final design, (5) production/execution, and (6) product introduction. This model was supplemented with job functions for each step of the process. For future research, the model should be further developed to provide a greater differentiating effect between the CIs and other industries. However, the model can be very useful for characterizing the CIs in a manner that is more adaptable to the ever-changing nature of these industries.
\end{abstract}

Keywords. Creative Industries; Creative Process; Job Functions; Characterization.

Cite paper as: Koehorst, M., van Deursen, A., van Dijk, J., De Haan, J., (2019). Exploring the Creative Industries: Toward a Classification by Process and Job Functions, Journal of Innovation Management, www.openjim.org, 7(3), 69-95. 


\section{Introduction}

Worldwide, the creative industries (CIs) are growing in terms of both value and the number of professionals working within the sector. According to the European Union (EU), the CIs have been experiencing a growth rate more than four times the EU's total average growth (KEA European Affairs, 2006), which indicates the importance of the CIs to the economy (UNCTAD, 2010). Therefore, governments worldwide are developing policies to help these industries remain competitive in an international and globalized market. However, to achieve this goal, a clear understanding of what characterizes the CIs is required. Currently, the CIs are primarily characterized in terms of specific professions, such as film director, editor, or architect (Urlings \& Braams, 2011), or industrial lines, such as broadcasting, performing arts, and advertising (Department for Culture Media \& Sport, 2014; Ministerie van EZ \& Ministerie van OCW, 2005). Because innovation is a key component of the CIs, these professions and industries are constantly evolving, which makes the CIs dynamic and fluid. Due to rapid innovation, products and services are introduced that would have seemed inconceivable just a decade ago; new technologies and applications are rapidly emerging. Among other things, these technologies are used to make business processes more efficient in a wide variety of sectors. This is why creativity and innovation are increasingly interwoven with other industries, which makes it counterproductive to use existing industrial lines to define this sector.

As past efforts to classify the CIs have severe limitations, Jones, Lorenzen, and Sapsed (2015) made a differentiation based on types of change. They argue that sectors within the CIs can be divided according to their response to different drivers of change. The types of change are "Preserve (slow change in semiotic codes and material base), Ideate (fast change in semiotic codes but slow change in material base), Transform (fast change in material base but slow change in semiotic codes), and Recreate (fast change in semiotic codes and material base)" (Jones et al., 2015, p. 13). An important driver of change is public policy. Preserve, as a type of change, is mainly concerned with sectors that can be described as cultural heritage, such as museums, and institutions for orchestras, ballet and opera. However, policy is becoming more concerned with the optimization of creative and human capital. The reciprocity of knowledge and spillovers to the wider economy become increasingly important as objectives of policy (Bakhshi, Cunningham, \& Mateos-Garcia, 2015; Cunningham \& Potts, 2015). For this reason, it is important to understand what kind of professionals work in the CIs, and what skills they need to reach their full creative potential.

The current structures used to delineate the CIs make it difficult to write such policy. Industries are often named after the principal product they produce. Apart from creativity, the commonality that merge the different industries in the CIs together, is unclear. Until this date there is no uniform consensus about the term creativity, which makes delineating of this sector even harder. In this paper, we explore how the CIs can be characterized without using strict and arbitrary industry lines or job functions. Alternatively, we suggest a process orientation to characterize the development of innovative products or services in the CIs. This process is supplemented by both creative and non-creative job functions needed in each phase. Understanding the process of creation is vital in understanding what job functions and the related human capital is needed to be creative and innovative in the modern workplace. By defining a process to which job functions 
can be linked, all professions involved in the creation of innovative products or services are considered, not only those jobs that are creative at their core. By doing so, not only will creative professionals be included, but a clearer overview of all professions that add to the economic value of the CIs will be achieved and human capital in the CIs can be adequately improved and utilized where needed. In addition, we believe that this approach to the characterization of the CIs is more dynamic and can capture the essence of this ever-changing sector. To help write policy for industries, besides those defined as cultural heritage, we aim to address the following questions:

- What work process characterizes creation and production in the creative industries?

- What are the job functions needed to successfully support this process?

To answer these questions, a set of semi-structured interviews were conducted with key players in the Dutch CIs. By answering these questions, we hope to gain better understanding of the CIs.

\section{Theoretical Framework}

\subsection{Creativity and Creative Industries}

Creativity is a much sought-after asset in workers in almost any industry, from automotive and advertisement to logistics and agriculture. However, the degree of creative intensity varies among the diverse professions in these industries. Furthermore, the understanding of creativity fluctuates within different contexts. Depending on the profession and industry in which people are employed, their idea of what creativity entails is likely to differ. Given the numerous definitions of creativity and the diversity of organizations and workers in the CIs, finding consensus on what should be considered part of this sector is a complex endeavor.

In scientific literature, the debate over a standard definition of creativity has been an issue since the middle of the twentieth century. Parkhurst (1999) claims that the lack of consensus about the definition complicates not only our understanding of the CIs but also the development of sufficient policy for nurturing creativity in students who are supposed to interact in the work environment of the twenty-first century. According to Runco and Garrett (2012), Stein (1953) provided the first "standard" definition of creativity, which combines two elements: (1) originality (e.g., innovation, novelty) and (2) effectiveness (e.g., fit, appropriateness). In this definition "effectiveness" is described as "a solution to a problem; a completed, communicable idea; or something tangible like an invention or work of art" (Parkhurst, 1999, p. 17). These two key elements seem to have been generally adopted by scholars and are combined in the definition of Amabile, Conti, Coon, Lazenby, and Herron (1996): "the productions of novel and useful ideas in any domain" (p. 1155). This definition is therefore often adopted by scholars in creativity research (e.g. Ernst, Hoyer, Krafft, \& Soll, 2017; Sarooghi, Libaers, \& Burkemper, 2015).

For the development of policies, however, a formal definition of creativity is not used as a starting point to understanding the CIs. Every country concerned with stimulating the CIs has its own framework for defining it, which is often based on industrial lines (Bakhshi, Freeman, \& 
Higgs, 2013; Braams, 2011; Department for Culture Media \& Sport, 2015; Ministerie van EZ \& Ministerie van OCW, 2005). However, due to spillovers to other industries, it is difficult to measure policy. The creative economy is more complex than the sum of these industries and might drive change throughout the whole economy (Potts \& Cunningham, 2010; Potts, Cunningham, Hartley, \& Ormerod, 2008).

\subsection{The Origin of the Creative Industries}

Since the development of the first DCMS mapping document (DCMS, 1998), the "cultural economy" has been gradually replaced by the creative economy. This change has promoted discussion about whether activities that are termed "cultural heritage" should be included in the definition of the CIs. Potts et al. (2008) note that the CIs are now classified on industrial lines, which is "an extension of the cultural industries definition to incorporate the copyright industries" (p. 2 ). This has remained unchanged since the first outline of the DCMS mapping document in 1998. However, this definition is too vague and inadequate to characterize the CIs (Flew \& Cunningham, 2010).

Nesta (2006) states that the purpose of the CIs is to exploit creative capital for commercial gain. This view is supported by Jones et al. (2015): "Even if there are elements of creativity in most human endeavor, not all industries are organized principally to take advantage of and capture the market value of human creativity"(p. 2) and UNCTAD: "(...) they [the CIs] comprise the cycle of creation, production and distribution of goods and services that use intellectual capital as their primary input" (2008, p. 5). UNCTAD underlines this concept by claiming that the services and goods produced by the CIs - in addition to creative content - should have economic value and be capable of being marketed (2008). This view clearly differs from the domain of "arts and cultural heritage" according to Rutten, Koops, and Roso (2010), who state that economic motives are subsidiary to the artistic motives and a certain aesthetic need. However, the importance of economic value for the CIs is also emphasized by Yue (2006), who explains that the CIs are essential to strengthening a country's competitiveness in global markets. These arguments show that there is an ongoing discussion about what to include in the CIs. Nevertheless, there is agreement on the inclusion of the following industries: publishing and literature; performing arts; music; film, video, and photography; broadcasting (television and radio); visual arts and crafts; advertising; design, including fashion; museums, galleries, and libraries; and interactive media (Flew \& Cunningham, 2010; UNCTAD, 2008). This outline clarifies that, although different efforts have been made to characterize the CIs, it is complicated for scholars and policymakers to depart from the original approach of classification by industry. It also emphasizes the need for an approach that makes it possible to write policy to improve the human and creative capital of professionals in the CIs that goes above and beyond cultural heritage and industrial lines.

To develop a flexible process characterization of the CIs, however, a starting point must be established. So, to obtain a better understanding of what transpires in the CIs, we use the definition of creativity provided by Amabile et al. (1996) as a starting point for our study: "the productions of novel and useful ideas in any domain" (p. 1155). 


\subsection{The Creative Process}

Creativity is at the core of the CIs, which UNCTAD (2008) describes as organizations that create, produce, and distribute services or goods with economic value for which intellectual capital is the most important input. Nonetheless, little has been published on the subject of a creative process to characterize organizations, let alone sectors. To date, the creative process as described in the literature focuses primarily on individual creation, which often follows the "four-stage model creative process": (1) preparation, (2) incubation, (3) illumination, and (4) verification (Guilford, 1950). However, Lubart (2000-2001) acknowledges that this model may need revision because it has been superficial since its conception. To define creativity, Torrance (1965) used a process approach in which the "sensing of difficulties, problems and gaps in information" (p. 8) is necessary to define and solve a problem. This is often referred to as problem analysis, which is considered essential for finding an adequate solution to a problem. When insufficient time is spent at the problem-analysis stage, there is a high risk of error (Römer, Leinert, \& Sachse, 2000). Bannerot (2003) further stresses the importance of problem analysis by stating that to obtain a clear overview of the client's needs, the process should entail (1) clarification of objectives, (2) establishment of requirements, (3) identification of constraints, and (4) establishment of job functions. The downside to the process-description of creativity by Torrance (1965) is that it does not differentiate between a typical creative endeavor and, for instance, a scientific one (Parkhurst, 1999).

Caniëls, De Stobbeleir, and De Clippeleer (2014) describe how different stages of the creative process require different incentives to maximize employee creativity. They summarize creativity as a process with three stages: idea generation, idea promotion, and idea implementation. In idea generation, multiple concepts are generated that might be possible solutions to a problem at hand. According to Wang (2013), this phase of concept generation - although very important - is typically characterized by a lack of structure. Although the approach of Caniëls et al. (2014) incorporates implementation and therefore has a wider scope than the model by Guilford (1950), it is still too limited for the purposes of this study because it focuses on individual creativity. Because a key component of the CIs is the economic value of marketable products, this aspect should be included in our process model.

\subsection{Job Functions}

The skillset required from workers in the twenty-first century is vastly different from the skills needed during and after the industrial revolution, which were focused on manual labor to a much greater extent. In current western society, knowledge - and the ideas generated with this knowledge - are seen as commodities (Anderson, 2008; UNCTAD, 2008). This principle of human capital and the knowledge and ideas of workers are a significant component of a successful creative organization. Knowledge is indispensable for innovation and development and therefore is directly correlated with economic growth (David \& Foray, 2003). This is why the CIs are seen as one of the sectors where great economic growth can be accomplished. Consequently, policy designed to support the growth of the CIs should be based on a clear understanding of these industries and of the people who work in them. 
Another method chosen to characterize the CIs is to approach this characterization from the perspective of the creative professional. Urlings and Braams (2011) counted the number of professionals working in job functions classified as creative because these professions are deemed important for stimulating economic growth. Bakhshi et al. (2013) proposed a focus on "creative intensity", which is the percentage of creatively occupied jobs in a sub-industry in comparison with the total number of jobs in that industry. However, for a complete overview of the economic value of the CIs, focusing on creative job functions is not sufficient. With these methods, the dynamic value of the CIs remains unclear because there might be many professions that are not classified as creative but that nevertheless play a crucial role in how a creative product or service transpires.

\section{Method}

Because very little scientific literature addresses the characterization of the CIs using a process approach, explorative research with qualitative methods of data collection and analysis was chosen for this study. Semi-structured interviews were used to gather information about the processes in CI organizations and the job functions that are important in this process.

\subsection{Research Setting: The Dutch Top Sector Creative Industries}

This study focuses on the Dutch CIs as one of nine knowledge-intensive sectors that receive special attention from the Dutch government and for which directed policies are developed to simulate growth. In the mapping document for creative activity in the Netherlands, which dates back to 2005, the CIs are classified as a collection of industrial segments in which a major part of the creative production occurs (Ministerie van EZ \& Ministerie van OCW, 2005). A division among three categories is proposed: (1) arts, (2) media and entertainment, and (3) creative and business services. Each of these categories is further divided into four stages: initial creation, production, distribution, and retail. These four stages are used to define a broad classification and a limited one (see Appendix A). As a starting point, the limited classification of the ministries of EZ (Economic Affairs) and OCW (Education, Culture and Science) (2005) was used (see Appendix A) because these are the organizations in which the creative process occurs and, as previously mentioned, there is a consensus on the industries included in this classification (Flew \& Cunningham, 2010; UNCTAD, 2008). Although we attempt to find a more dynamic classification of the CIs, this classification helped us to achieve the necessary variety within the sample.

\subsection{Sample}

The study focused on key players in the Dutch CIs. A list of different industries in the creative sector was constructed, after which potential participants were selected using LinkedIn and the researchers' personal networks. For the final selection, criterion-based sampling was used to ensure that every element of interest for the research was covered. More specifically, we used maximum-variation sampling so that each of the different constituents of the CIs was included 
(Ritchie, Lewis, \& Elam, 2003). A total of 23 interviews were held with 24 participants. Of the participants, $33.3 \%$ were female $(n=8)$. Among these were CEOs/founders $(n=8)$, working professionals $(n=3)$, HR managers $(n=2)$, recruiters $(n=2)$ and board members $(n=2)$. Participants working in the following industries were included: media, advertising, graphic design, game development, software development, publishing, architecture, Dutch design, journalism, music, and fashion (Table 1).

Table 1. Industries and Job Functions interviewees

\begin{tabular}{llllll}
\hline$\#$ & Industry & $\begin{array}{l}\text { Function } \\
\text { interviewee }\end{array}$ & Industry & $\begin{array}{l}\text { Function } \\
\text { interviewee }\end{array}$ \\
\hline 1 & Overarching & CEO & 12 & Publishing/media & Managing dir. \\
\hline 2 & Architecture & Founder/CEO & 13 & Publishing/media & HR chief \\
\hline $3 \mathrm{a}$ & Architecture & HR manager & 14 & Media & Manager \\
\hline 3b & Architecture & $\begin{array}{l}\text { Business } \\
\text { Developer }\end{array}$ & 15 & Advertising/media & Founder/CEO \\
\hline 4 & Architecture/education & Board member & 16 & Advertising/media & Film director \\
\hline 5 & Education & Board member & 17 & Fashion & Founder/CEO \\
\hline 6 & Education & Head of dept. & 18 & Fashion/education & Head of dept. \\
\hline 7 & Education/gaming & Head of dept. & 19 & Textiles/design & Founder $/$ CEO \\
\hline 8 & Gaming & Founder/CEO & 20 & Music & Programmer \\
\hline 9 & Serious gaming & Recruitment & 21 & Music & Founder $/$ CEO \\
\hline 10 & Serious gaming & Founder/CEO & 22 & Journalism & Independent \\
\hline 11 & Publishing/media & Interim director & 23 & Museum & Interim director \\
\hline
\end{tabular}

\subsection{Procedure}

After selection, participants were contacted via e-mail to make an interview appointment. A semistructured interview approach was used to collect information. By doing so, open-ended questions could be adapted to the participants' specific industry. Of the 23 interviews, 22 were individual interviews (with one participant). The interviews were recorded and later transcribed.

Every interview began with the recording of informed consent, after which the first author asked the participant to describe the company in which he or she worked and the kind of work the participant did for the company. As the interview continued, the questions focused on processes and job functions. After the introductory questions, participants were asked what kind of products or services they provided and how these were developed. Participants were asked to draw the process of product creation on a sheet of paper. This drawing served as a guideline throughout the rest of the interview. After the process was drawn and discussed in depth, participants were asked what job functions or professions could be linked to the different steps of the process. These professions were written on blue pieces of paper and were placed near the corresponding steps of the process. 


\subsection{Data Analysis}

All interviews were transcribed and then coded with the use of ATLAS.ti. Content analysis was used to derive a codebook. The codebook contained all codes subdivided into themes. The themes were mostly predetermined by the interview questions (i.e., process, job functions, CI) (see Appendix B). These themes were used to categorize the codes, which were extracted during content analysis on basis of the interviewees' answers (e.g., the code "designer" was added to the theme "job functions" when an interviewee mentioned a designer as someone who worked in the CIs). These codes were added to quotes referring to the construct of the code. After the content analysis, relational analysis was used to identify similarities in coding and merge overlapping codes. The analyses of the 23 interviews resulted in 8 themes with 138 codes (Table 2). A ninth theme (steps) was added to connect the different steps of the process, as mentioned by the participants, to a number to achieve an order in the steps. Some of the themes had multiple subthemes to differentiate several concepts and contextual elements (see Appendix B). The interrater agreeability between two raters had a Cohen's Kappa of .67.

Table 2. Themes of the codebook with the number of subthemes and labels

\begin{tabular}{lcc}
\hline Theme & \# of subthemes & \# of labels \\
\hline Creativity & 0 & 3 \\
\hline CIs & 2 & 12 \\
\hline Culture & 0 & 4 \\
\hline Job functions & 3 & 34 \\
\hline Organization & 0 & 9 \\
\hline Other & 0 & 1 \\
\hline Process & 4 & 43 \\
\hline Skills & 5 & 27 \\
\hline
\end{tabular}

\section{Results}

In the following section, the results of the interviews are discussed based on the concepts of the process and job functions.

\subsection{The CI Process Model}

Based on the content analysis of the interviews and the drawings, steps in the work process within the CIs could be distinguished. Because a characteristic of the CIs is adding economic value, these steps involve the introduction of products into the marketplace. The steps are elucidated here.

\section{Problem analysis.}


Problem analysis was often mentioned as an important prerequisite for a successful creative process. Without a clear definition of the problem, it is unlikely that the final product will meet the client's expectations. Participants explained that the problem analysis stage helps to define the exact question of the client and therefore the relevant problem to be solved. Clients frequently have a fixed idea about what the solution to the problem should be, even before the design process has begun. Problem analysis helps to focus on the final goal instead of the way in which this goal is achieved. During problem analysis, all pieces of information are collected. According to the participants, a characteristic of creative problem solving is that many options for solving one problem are explored, so having all the information is crucial. As one of the participants put it,

"In general, they [the clients] say, 'We want $X$ ', and a firm then says, 'Are you sure you want $X$ ?' 'Yes'. 'I think you have a problem that you could want to solve with $X$, but it could also be something else'. So, yeah, maybe that is more or less the difference between knowing you buy bread or somebody saying, 'You are hungry, that is the problem, and maybe you want bread, or maybe something else'."

Respondents indicated that in the creative process, the solution starts with determining the "right" problem. This is not always clear to the client, even though the client might think it is.

\section{Concept generation.}

Participants suggested that concept generation starts with sketches or rough ideas that have been generated in response to the needs and criteria that are derived from problem analysis. They stated that during the concept generation stage, various directions are explored:

"... on the basis of the analysis, you will often go to the concept phase, in which different directions are developed".

With the help of the output of problem analysis, initial sketches or manifestations of what the final result could be are developed without going into detail. A concept expresses the idea that eventually should be conveyed to users once the product is completed. It is the first step toward the final idea. It is common for multiple concepts or ideas to be explored during this stage. A combination of concepts can be applied in the finalized product. In general, during the concept generation stage, there are very few limitations. Because everything is still open and all options can be explored, this is where creativity can flow most freely and creative intensity is at its peak.

\section{Design.}

Design was often divided into multiple stages by the participants. Whereas during the concept generation stage various ideas are given a rough form or are sketched, in design, one or more of those ideas is further explored and perhaps executed. The participants used many different names for the design stages, such as schematic design, provisional design, technical design, contextual design and final design. However, almost all of them made a distinction between the first phases of design, in which more freedom was permitted and ideas were not yet set in stone, and the stricter final design, in which details were worked out and the design was finalized before it went to the production, execution or engineering phase (Fig. 1). 
"... with a concept design (...), that is more or less the dating phase: (...) are we the right match? And if you conclude, we want to date each other, then you are going to objectify that [the concept design]. Then you make a schematic design, which means you have clearer objectives...".

\section{Iterations.}

Iterations are represented in the model by the arrows moving in different directions (Fig. 1). Iterations are loops in the process; developers are continuously testing and altering the product. While doing so, much of the initial ideas might perish. Iterations were often mentioned in combination with "scrum" or "agile development", methods that are used in the CIs. As one of the interviewees explained:

"Iterations is THE keyword in the creative industries. (...) You just start very small, you make something, you test it, you improve it, you test it, you improve it, you test it, you improve it, you test. So you go in short loops towards the endpoint".

Iterations mostly appear in the concept generation and design stages, although during design, it might be beneficial to go back to the problem analysis stage to obtain extra information

\section{Production/execution and product introduction.}

As previously discussed, the CIs are characterized by the ability to achieve commercial gain by marketing novel and useful ideas. This is why the production and execution of the designs and the introduction of those products into the marketplace are a crucial part of the creative process for the CIs. Without a successful and well thought out introduction of those products, the CIs would cease to exist. Indeed, part of the CIs' activities is to creatively market products or services for clients. As this interviewee described it:

"What does a creative person do? They work on an assignment and at some moment it is finished, 'Oh, the assignment is finished. What should I do next?' There is another process behind it, among others, business development."

Companies specializing in marketing products for clients go through all the steps of the process themselves to introduce these products into the marketplace. In these instances, the end result of the process is not the client's product but the marketing campaign created by the company. As the product nears finalization, creative intensity degrades because the choices made are more definitive.

Considering all these steps, a model of the process derived from the interviews and drawings is shown in Fig. 1. As shown in Figure 1, the start of the process can be either triggered by demand from either a client or the market, or by opportunities from the market or society. 


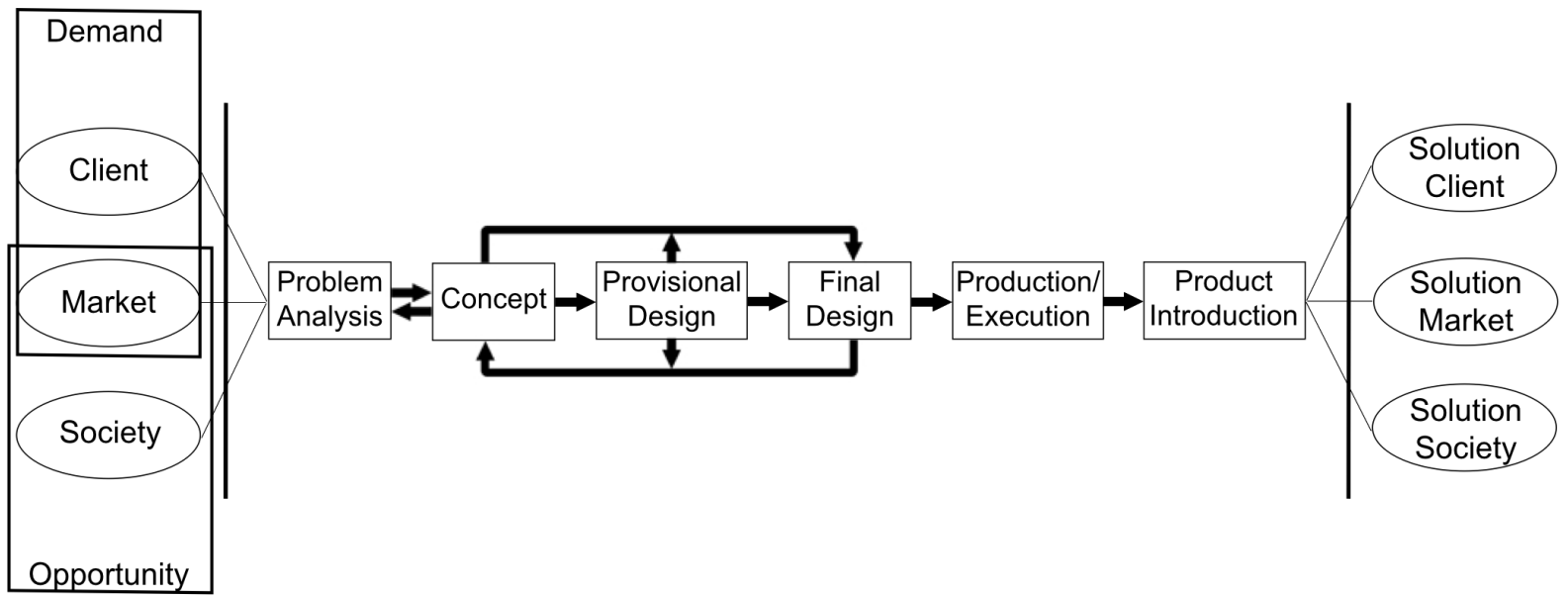

Fig. 1. Process model characteristic for product or service development in the CIs

\subsection{Job Functions}

Since the kind of sectors included in the CIs display a lot of differentiation in the principal products they produce, the job functions found within these sectors differ greatly. However, some overlap in groups of job functions can be found, even though the manner in which these jobs are performed, and the products they produce are un-alike. To group these job functions, we compared the job functions mentioned by the respondents with the creative job functions as summarized by Urlings and Braams (2011). With this comparison, a few things stand out. The job functions Urlings and Braams (2011) characterize as creative are divided in three categories, namely arts, media and entertainment and creative and business services. The third category is predominantly related to job functions in architecture and urbanism. However, a great deal of the job functions included by Urlings and Braams (2011) were described by the respondents as less creative, or even non-creative. Examples are: constructor, engineer or managing partner. In other categories Urlings and Braams (2011) included job functions that were characterized by the respondents as non-creative, mainly with regards to project management for film, publishing and new media, and more executing job functions like programmer or engineer. Furthermore, many functions named by respondents were not even included: job functions related to game design - either for entertainment or serious games - and job functions related to fashion design were absent in their framework.

Table 3. job functions mentioned by respondents and their corresponding job function group in the model

\begin{tabular}{llll}
\hline $\begin{array}{l}\text { job function } \\
\text { group in } \\
\text { model }\end{array}$ & $\begin{array}{l}\text { Examples } \\
\text { mentioned by } \\
\text { respondents }\end{array}$ & Sector & $\begin{array}{l}\text { Corresponding job } \\
\text { function by Urlings and } \\
\text { Braams }(2011)^{*}\end{array}$ \\
\hline Designer & Artist & Gaming & - \\
& Game designer & Gaming & -
\end{tabular}




\begin{tabular}{|c|c|c|c|}
\hline $\begin{array}{l}\text { job function } \\
\text { group in } \\
\text { model }\end{array}$ & $\begin{array}{l}\text { Examples } \\
\text { mentioned by } \\
\text { respondents }\end{array}$ & Sector & $\begin{array}{l}\text { Corresponding job } \\
\text { function by Urlings and } \\
\text { Braams }(2011)^{*}\end{array}$ \\
\hline & Visual designer & Gaming & - \\
\hline & & Marketing/media & $\begin{array}{l}\text { Book illustrator, lightning } \\
\text { sketcher, decor-, marketing-, } \\
\text { graphic designer } \\
\text { (intermediate) }\end{array}$ \\
\hline & Fashion designer & Fashion & - \\
\hline & Textile designer & Fashion & - \\
\hline & Architect & Architecture & $\begin{array}{l}\text { Urbanist; architect, } \\
\text { construction engineer }\end{array}$ \\
\hline & Architect (Interior) & Architecture & $\begin{array}{l}\text { Interior designer; architect, } \\
\text { construction engineer }\end{array}$ \\
\hline & $\begin{array}{l}\text { Architect } \\
\text { (Landscape) }\end{array}$ & Architecture & Garden- and landscape \\
\hline & & & architect \\
\hline & Interaction designer & Marketing/media & - \\
\hline & & Gaming & - \\
\hline & Photographer & Marketing/media & $\begin{array}{l}\text { Photographer, film- and tv- } \\
\text { camera operator, film editor } \\
\text { or mechanic, photo } \\
\text { laboratory } \\
\text { operator (intermediate) } \\
\text { Instrumentalist, composer, } \\
\text { conductor (excl. choir), } \\
\text { songwriter }\end{array}$ \\
\hline & Sound designer & Gaming & - \\
\hline & Curator & Museums & - \\
\hline & Composer & Music & $\begin{array}{l}\text { Instrumentalist, composer, } \\
\text { conductor (excl. choir), } \\
\text { songwriter }\end{array}$ \\
\hline \multirow[t]{3}{*}{ Strategist } & Strategist & Marketing/media & - \\
\hline & & Gaming & - \\
\hline & Business Developer & Architecture & - \\
\hline
\end{tabular}




\begin{tabular}{|c|c|c|c|}
\hline $\begin{array}{l}\text { job function } \\
\text { group in } \\
\text { model }\end{array}$ & $\begin{array}{l}\text { Examples } \\
\text { mentioned by } \\
\text { respondents }\end{array}$ & Sector & $\begin{array}{l}\text { Corresponding job } \\
\text { function by Urlings and } \\
\text { Braams (2011) }\end{array}$ \\
\hline & Researcher & Gaming & - \\
\hline & Booker & Music & - \\
\hline \multirow[t]{12}{*}{ Project Manager } & Production assistant & Television & - \\
\hline & Content manager & Publishing & - \\
\hline & Film director & Film & Director theatre, film \\
\hline & Floor manager & Film & - \\
\hline & Art director & Marketing/media & - \\
\hline & & Gaming & - \\
\hline & & Fashion & - \\
\hline & Creative director & Film & - \\
\hline & Project manager & Gaming & - \\
\hline & & Architecture & - \\
\hline & & Museums & - \\
\hline & Producer & Marketing/media & - \\
\hline \multirow[t]{5}{*}{ Engineer } & Programmer & Gaming & - \\
\hline & & Marketing/media & - \\
\hline & $\begin{array}{l}\text { Construction } \\
\text { engineer }\end{array}$ & Architecture & Designer-constructor \\
\hline & Installation engineer & Architecture & $\begin{array}{l}\text { Designer-constructor energy, } \\
\text { telecommunication technique, } \\
\text { electric motors, electronics }\end{array}$ \\
\hline & Knitting specialist & Fashion & - \\
\hline \multirow{4}{*}{$\begin{array}{l}\text { Marketing } \\
\text { Manager }\end{array}$} & Marketer & Publishing & - \\
\hline & & Museums & - \\
\hline & Sales manager & Publishing & - \\
\hline & Sales director & Fashion & - \\
\hline
\end{tabular}

* If applicable.

Some of the job functions were absent in the framework of Urlings and Braams (2011), this could also be due to the fact that some of the job functions as mentioned by the respondents were considered to be non-creative. 


\section{Professional creativity.}

To be able to connect job functions to the different stages of the model, we first need to obtain an understanding of the degree of creativity for the involved professionals. Therefore, we take a closer look at what is viewed as a creative professional.

As noted by many of the interviewees, creativity is a skill or trademark that is desired in most, if not all, professionals in the twenty-first century. In that sense, it should be used in the general line of work. Most interviewees responded to the questions about which job functions they considered creative by stating that it is preferable for all employees to possess some degree of creativity to help them with their daily activities. Initially, they felt reluctant to appoint certain job functions as being more creative than others:

“... I actually think that, of everybody who works for us, a certain degree of creativity is required (...) Except for the bookkeeper - that is somebody we don't need because of his creativity - but for all the production-oriented people, (...) we expect a certain degree of creativity".

For creative professionals, creativity is the aspect that makes them successful; it is the aspect around which their jobs revolve. It is why clients come to them: to think of something no one else had thought of. Participants noted that some clients tend to take the place of the designer, making the creative professional an executor instead of a creator and innovator. However, being the innovator and not the executor is a very important trademark of the creative professional.

To discover what they viewed as truly creative, the participants were asked to give their own definition of creativity. Many interviewees mentioned "out-of-the-box" as a phrase that instantly came to mind when asked about creativity. Almost all participants mentioned creation or finding new solutions as an aspect of creativity, although none of them referred to both innovativeness and effectiveness as key factors of creativity. The closest to a definition was given by this participant:

"Creativity is a part of the creative/artistic process. Creativity means that you are able to make a new composition from an existing context and situation. So that is actually the creative part in it. But it is also, in the artistic/creative process, there is also a part-if you are talking about the development process - that is just repetition and doesn't have anything creative in itself. (...) But the creative moment itself is the moment that you take existing elements and make something that is new to you".

Participants acknowledged the difference between creativity being at the core of someone's profession and creativity as a skill to be better at a job. Thus, a distinction can be made between "creative job functions" (e.g., designers, researchers, strategists, art directors) and "non-creative job functions" (e.g., producers, project leaders). Even though all job functions are equally important for efficient product development, most non-creative job functions (with the exception of the project leader) could be viewed as supporting or executive roles.

Creativity was considered a more important skill in the beginning of the process, when new ideas had to be generated. As the process of development continues, the margin for creativity diminishes and the more execution-related job functions (i.e., functions that realize the ideas conceived in earlier stages of the process) begin to play a larger role. 


\section{The CIs' Process Model Supplemented with Job Functions}

In the following section, the process model described earlier is supplemented with the job functions mentioned by the interviewees. Considering the breadth of the CIs, these job functions are formulated as groups with a common underlying incentive.

\section{Problem analysis.}

Job functions involved in this stage, according to the participants, are business developers, strategists and researchers who determine what information is needed to successfully execute the project. These job functions might be executed by the same person - or possibly even the designer - depending on the size of the organization:

"... that job function is just united in one person in the way I just said. It is, however, often the case that the analysis is performed by people who actually understand how you can build something after that."

When problem analysis is completed, a team can be assembled that will design and develop the solution. If a project manager is appointed, he or she will be involved in this stage of the process as well.

\section{Concept generation.}

In this stage, creativity can flow freely. This is where creative professions such as designers come up with multiple ideas, only loosely guided by project management.

\section{Design and production/execution.}

Depending on the product or service developed, designers, architects, game designers, or art directors are most involved in these stages. Engineers are involved in this stage to begin the execution of the product. Through iterations of design and production/execution, designers and engineers work together. As the process continues - from concept generation, to provisional design, to final design - the degree of freedom for creativity becomes increasingly restricted. However, through iterations, the product is continuously tested, analyzed and improved, so the degree of freedom and the people involved might be dynamic.

"So, that constructor, he will say, 'I want concrete pillars. And I want concrete beams, or steel beams'. Give those to his engineers, and they will incorporate that in that model. Those get slid into each other. Every week it gets taken apart and put together again. And this is how the design gets developed further".

As another example of how different job functions are connected to different steps of the process, depending on the degree of finalization of the product, one architect said:

"We [the architects] are very focused on the concept phase, and the co-architect is actually more focused on the execution phase".

\section{Product introduction.}

The product introduction-phase is concerned with introducing the finalized product into the market. The importance of this step was emphasized by this interviewee:

"I think product development is real creation, but my eyes have really been opened the last 
few years to what creativity means if you are talking about graphics and about marketing because for me, this all has to do with the same thing. That is, somebody sees something, feels something, that it gives you a warm feeling-to keep it vague-ultimately making you want to buy the product or use it. And that is, on the one side, dependent on the product, but since we founded [the company] and did the whole branding, the way in which we started selling, that really made a difference in how people look at you as a brand and, yeah, we really saw a difference between the old branding and the new branding and what it adds to the fact that your product is just interesting. (...) I think that that branding (...) resulted in more conversion".

This statement shows that to generate value, introduction into the market and the way a product is branded are very important. This is why strategists and marketers are important for economically thriving CIs.

A general overview of what job function groups play a role in the different steps of the creative process model is shown in Figure 2.

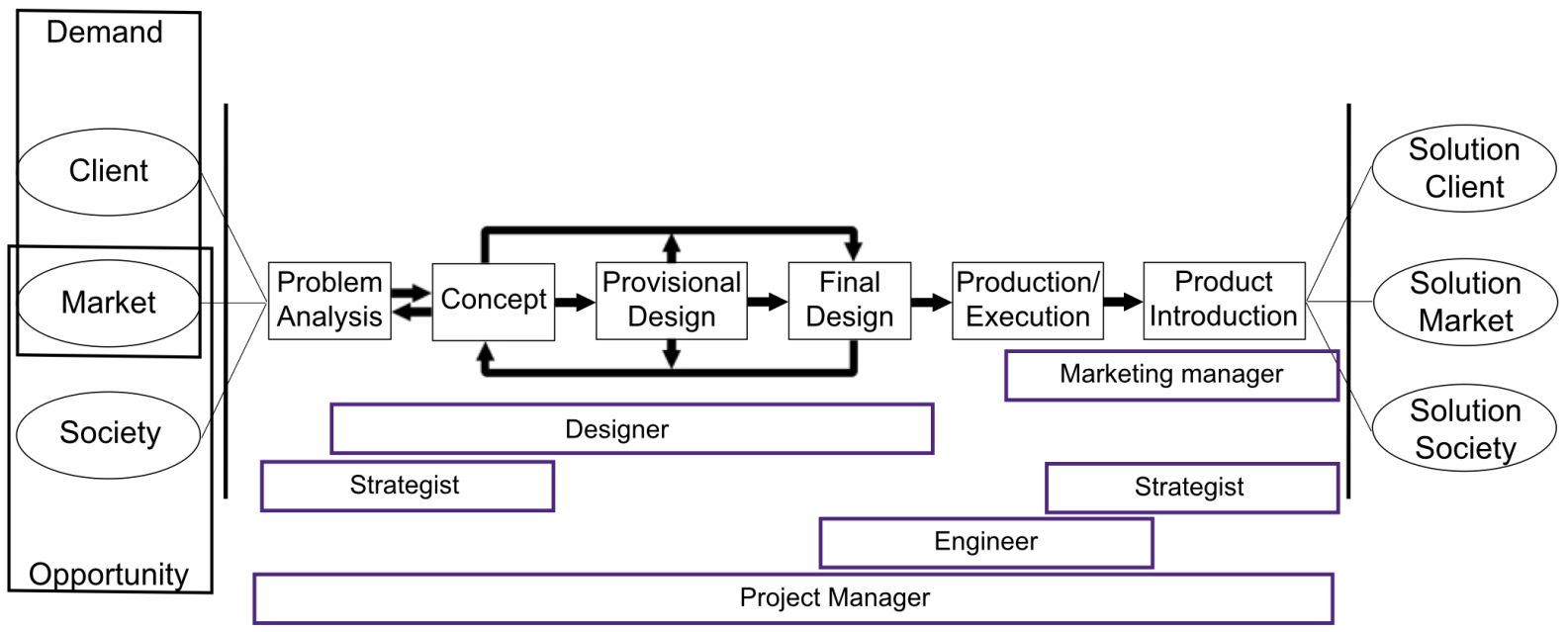

Fig. 2. Process-model supplemented with job function groups.

\section{Discussion}

\subsection{Main Findings}

Because the definition of the CIs is now based on seemingly arbitrary industrial lines, the current study aimed to find a process that could characterize the CIs and help with the development of policy by linking job functions to this process. Policy regarding the CIs is now mainly focused on maintaining existing structures that would be difficult to uphold without subsidies or other kinds of incentives from governmental structures (Jones et al., 2015). However, to improve the economy by optimizing the innovative force of the CIs a different kind of policy is needed. That is why we developed a process to delineate the CIs in a manner that is more dynamic in comparison 
to frameworks currently used. This dynamic property is important, since the industries for which policy has to be written are more dynamic than structures in the past. Also, work has changed a lot in the last few decades, which has greatly impacted the required human capital. By linking job functions to the work process, it can help in understanding what skills employees need to innovate. This, in turn, can help in writing policy to optimize the innovative power of the CIs. With respect to the first question (what work process characterizes creation and production in the creative industries?), we derived a six-step process: problem analysis, concept generation, provisional design, final design, production/execution, and product introduction (Fig. 1). This process partly overlaps the generation and implementation of ideas (Caniëls et al., 2014), but adds the characterization of a method for collective development instead of focusing on individual creation. The proposed process model is unique in a way that it is meant to be applicable to the CIs as an economy that uses their products as commodities to create value. This has been described as imperative for the CIs (Nesta, 2006; Rutten et al., 2010; UNCTAD, 2008; Yue, 2006). One element that makes this process specifically suitable for the CIs is the role of the problem analysis phase. In the CIs, when this phase is successfully executed, the goal (i.e. what to achieve with the solution) is clear, but the way to achieve the goal (i.e. the solution) is not. Therefore, to achieve the goal, the solution must be both novel - since it is not yet known - and useful. This is in line with the definition of creativity as given by Amabile et al. (1996).

Two components distinguish this process from processes in other industries. Firstly, iterations are an indispensable aspect of work in the CIs. These iterations serve as a check, to prevent a mismatch between the question asked and the final solution being given. In other industries a funnel-like approach to product development is more common, in which taking a step back is difficult. Secondly, the CIs are not just demand-driven. Many products are developed when a person or organization sees an opportunity in the market or in society. Both demand and opportunity are depicted in the work process (Fig. 1).

To follow up on the process model, we attempted to answer the question of what job functions are needed to successfully support this process. We found that, regarding the creative process, a distinction can be made between "core creative job functions" and supporting and executive job functions, which are generally considered less creative. These "non-creative job functions", however, are very important. By connecting all these job functions to the model, we make a case for our approach by acknowledging that it is not only those job functions that are creative at their core that are needed for the creation of economic value in the CIs. Supporting roles such as those of project managers help to complete the process fluently and enable the core creative professionals to work to the best of their ability. This central role of creative job functions is shown in Table 3. Job functions included in the framework of creative job functions in the Netherlands by Urlings and Braams (2011) are mostly prominent in the designer sub-group, which plays the largest role in the beginning of the process. This is where creativity can flow the most freely. The absence of the other job functions in the framework of Urlings and Braams (2011) shows that our process has the unique ability to include all job functions needed in the CIs and is therefore more suitable to use when writing policy for this sector. By using the process approach, policies to improve skills of all professionals in the CIs can be developed. 


\subsection{Limitations and Future Research}

Although we found a model that seems applicable to most - if not all- developmental activities in the CIs, the capacity to differentiate between the CIs and other industries might be improved upon. However, our goal was to develop a model that could be used to help stimulate growth in the CIs by looking at the human capital needed, and it is our belief that this model enables just that. Still, for future research, the model could be improved to make a better distinction between different industries.

The identified model can be used to study and better understand the CIs. It provides input for processes and the important job functions that are required at each stage of the process. Future studies could research the most important skills among workers at each stage of the process.

\subsection{Concluding Remarks}

We aimed to find a process that could help us identify and understand the most important aspects of the CIs with regard to how goods and services are developed. This was done by means of a series of interviews with key players in the Dutch CIs. In the Netherlands the CIs receive extra resources to make them competitive players in the international market in hopes of stimulating the Dutch economy as a whole. By identifying a process and connecting the most important job functions to that process, the focus can shift from the level of the working individual or an organization as a single entity to how professionals interact within the sector. In many instances, this interaction will be across the borders of an organization. Because it is not just the creative individual but a team of professionals who make the execution and launch of a product successful, the process can be used to approach issues of efficiency and effectiveness on a higher level. As Carnevale and Smith (2013) state, effectivity and efficiency are important elements that determine an organization's ability to improve productivity and stay competitive.

\section{References}

Amabile, T. M., Conti, R., Coon, H., Lazenby, J., \& Herron, M. (1996). Assessing the work environment for creativity. The Academy of Management Journal, 39(5), 1154-1184.

Anderson, R. (2008). Implications of the information and knowledge society for education. New York: Springer.

Bakhshi, H., Cunningham, S., \& Mateos-Garcia, J. (2015). Public Policy for the Creative Industries. In C. Jones, M. Lorenzen, \& J. Sapsed (Eds.), Oxford Handbook of Creative Industries (1 ed., pp. 465-485). Oxford: Oxford University Press.

Bakhshi, H., Freeman, A., \& Higgs, P. (2013). A dynamic mapping of the UK's creative industries. Retrieved at December 15, 2016 from http://www.nesta.org.uk/publications/ dynamic-mapping-uks-creative-industries 
Bannerot, R. (2003). An exercise in problem definition in an early design course. Paper presented at the American Society for Engineering Education Annual Conference \& Exposition, Nashville, Tennessee.

Braams, N. (2011). Onderzoeksrapportage creatieve industrie. Retrieved at December 15, 2016 from https://www.cbs.nl/nl-nl/onze-diensten/methoden/onderzoeksomschrijvingen/aanvullende\% 20onderzoeksbeschrijvingen/onderzoeksrapportage-creatieve-industrie

Caniëls, M. C. J., De Stobbeleir, K., \& De Clippeleer, I. (2014). The antecedents of creativity revisited: A process perspective. Creativity and Innovation Management, 23(2), 96-110. doi:10.1111/caim.12051

Carnevale, A. P., \& Smith, N. (2013). Workplace basics: The skills employees need and employers want. Human Resource Development International, 16, 491-501. doi:10.1080/13678868.2013.821267

Cunningham, S., \& Potts, J. (2015). Creative industries and the wider economy. In C. Jones, M. Lorenzen, \& J. Sapsed (Eds.), Oxford Handbook of Creative Industries (1 ed., pp. 387-404). Oxford: Oxford University Press.

David, P. A., \& Foray, D. (2003). Economic fundamental of the knowledge society. Policy Futures in Education - An e-Journal, 1(1), 1 - 22.

DCMS. (1998). Creative Industries Mapping Documents 1998. Retrieved at November 14, 2016 from https://www.gov.uk/government/publications/creative-industries-mapping-documents-1998

Department for Culture Media \& Sport. (2014). Creative industries economic estimates Retrieved at November 17, 2016 from https://assets.publishing.service.gov.uk/government/ uploads/system/uploads/attachment_data/file/271008/Creative_Industries_Economic_Estimates_ -_January_2014.pdf

Department for Culture Media \& Sport. (2015). Creative Industries: Focus on employment. Retrieved at November 29, 2016 from https://assets . publishing. service.gov . uk/government/ uploads/system/uploads/attachment_data/file/439714/Annex_C_-_Creative_Industries_ Focus_on_Employment_2015.pdf

Ernst, H., Hoyer, W. D., Krafft, M., \& Soll, J.-H. (2017). Virtual Co-Creation with Customers in the Early Stages of New Product Development. Retrieved at April 2, 2019 from https: //papers.ssrn.com/sol3/papers.cfm?abstract_id=3053800

Flew, T., \& Cunningham, S. (2010). Creative Industries after the First Decade of Debate. The Information Society, 26(2), 113-123. doi:10.1080/01972240903562753

Guilford, J. P. (1950). Creativity. American Psychologist, 5, 444-454.

Jones, C., Lorenzen, M., \& Sapsed, J. (2015). Creative Industries: A Typology of Change. In C. Jones, M. Lorenzen, \& J. Sapsed (Eds.), Oxford Handbook of Creative Industries. Oxford: Oxford University Press.

KEA European Affairs. (2006). The economy of culture in Europe. Retrieved at 13 December, 2016 from http://ec.europa.eu/assets/eac/culture/library/studies/cultural-economy_ en.pdf 
Lubart, T. I. (2000-2001). Models of the creative process: Past, present and future. Creativity Research Journal, 13, 295-308.

Ministerie van EZ, \& Ministerie van OCW. (2005). Creativiteit in kaart gebracht. Mapping document creatieve bedrijvigheid in Nederland. Paper presented at the Cultuur en Economie, Den Haag.

Nesta. (2006). Creating growth. How the UK can develop world class creative businesses. Retrieved at November 17, 2016 from http://www.nesta.org.uk/publications/creating-growth

Parkhurst, H. B. (1999). Confusion, lack of consensus, and the definition of creativity as a construct. The Journal of Creative Behavior, 33(1), 1-21.

Potts, \& Cunningham, S. (2010). Four models of the creative industries. International Journal of Cultural Policy, 120(1), 163-180.

Potts, Cunningham, S. D., Hartley, J., \& Ormerod, P. (2008). Social network markets: a new definition of the creative industries. Journal of Cultural Economics, 32(3), 167-185.

Ritchie, J., Lewis, J., \& Elam, G. (2003). Designing and Selecting Samples. In J. Ritchie \& J. Lewis (Eds.), Qualitative Research Practice. A Guide for Social Science Students and Researchers London: SAGE Publications.

Römer, A., Leinert, S., \& Sachse, P. (2000). External support of problem analysis in design problem solving. Research in Engineering Design - Theory, Applications, and Concurrent Engineering, 12(3), 144-151. doi:10.1007/s001630050029

Runco, M. A., \& Garrett, J. J. (2012). The standard definition of creativity. Creativity Research Journal, 24 (1), 92-96. doi:10.1080/10400419.2012.650092

Rutten, P., Koops, O., \& Roso, M. (2010). Creatieve industrie in de SBI 2008 bedrijfsindeling. Retrieved at March 24, 2017 from http://docplayer.nl/3225909-Creatieve-industrie-in-de-sbi-2008-b html

Sarooghi, H., Libaers, D., \& Burkemper, A. (2015). Examining the relationship between creativity and innovation: A meta-analysis of organizational, cultural, and environmental factors. Journal of Business Venturing, 30, 714-731. doi:10.1016/j.jbusvent.2014.12.003

Stein, M. I. (1953). Creativity and culture. Journal of Psychology, 36, 31-322.

Torrance, E. P. (1965). Rewarding creative behavior: Experiments in classroom creativity. Englewood Cliffs, NJ: Prentice-Hall.

UNCTAD. (2008). Summary Creative Economy Report 2008 - The challenge of assessing the creative economy: towards informed policy-making. Retrieved at November 22, 2016 from http: //unctad.org/en/docs/ditc20082cer_en.pdf

UNCTAD. (2010). Creative economy report 2010 - Creative economy: A feasible development option. Retrieved at November 21, 2016 from https://unctad.org/en/docs/ditctab20103_ en.pdf

Urlings, N., \& Braams, N. (2011). Creatieve industrie in Nederland. Creatieve beroepen. Retrie- 
ved at December 16, 2016 from https://www.cbs.nl/-/media/imported/documents/2011/09/ 2011-creatieve-industrie-creatieve-beroepen.pdf

Wang, H.-H. (2013). A case study on design with conceptual blending. International Journal of Design Creativity and Innovation, 2(2), 109-122. doi:10.1080/21650349.2013.830352

Yue, A. (2006). Cultural governance and creative industries in Singapore. International Journal of Cultural Policy, 12(1), 17-33. doi:10.1080/10286630600613176 


\section{Appendix A}

Division of the creative sector in The Netherlands according to the Ministry of Economic Affairs and the Ministry of Education, Culture and Science

\begin{tabular}{|c|c|c|}
\hline Creation & Material production & Distribution and retail \\
\hline \multicolumn{3}{|l|}{ Arts } \\
\hline Visual arts and photography & Visual arts and photography & $\begin{array}{l}\text { Museums and exposition } \\
\text { rooms, exhibitions, art } \\
\text { auctions, art lending, galleries }\end{array}$ \\
\hline $\begin{array}{l}\text { Performing arts: music, dance } \\
\text { and theatre }\end{array}$ & $\begin{array}{l}\text { Production of performing arts: } \\
\text { music, dance and theatre }\end{array}$ & $\begin{array}{l}\text { Theatres and concert halls, } \\
\text { event halls }\end{array}$ \\
\hline \multirow[t]{2}{*}{$\begin{array}{l}\text { Recreation centres, } \\
\text { organization of cultural events }\end{array}$} & $\begin{array}{l}\text { Reproduction and publisher of } \\
\text { CDs and DVDs }\end{array}$ & CD- and DVD-stores \\
\hline & Recreation centres, event halls & $\begin{array}{l}\text { Recreation centres, cultural } \\
\text { events, event halls }\end{array}$ \\
\hline \multicolumn{3}{|l|}{ Media and entertainment } \\
\hline $\begin{array}{l}\text { Movie: Scenario, scriptwriting } \\
\text { and other pre-production }\end{array}$ & $\begin{array}{l}\text { Film production, including } \\
\text { supporting activities }\end{array}$ & $\begin{array}{l}\text { Film distribution, cinemas, film } \\
\text { theatres and video stores }\end{array}$ \\
\hline Same for radio and television & $\begin{array}{l}\text { Production of radio- and } \\
\text { television programmes }\end{array}$ & Broadcasting organizations \\
\hline $\begin{array}{l}\text { Writing: novels, poetry, } \\
\text { non-fiction }\end{array}$ & Publishing and book printing & Public libraries, book stores \\
\hline Journalism & $\begin{array}{l}\text { Publishing and printing of } \\
\text { newspapers }\end{array}$ & $\begin{array}{l}\text { Public libraries, shops in book, } \\
\text { magazines and newspapers }\end{array}$ \\
\hline \multicolumn{3}{|l|}{$\begin{array}{l}\text { Creative and business } \\
\text { services }\end{array}$} \\
\hline $\begin{array}{l}\text { Industrial design, fashion } \\
\text { design, graphical design }\end{array}$ & $\begin{array}{l}\text { Manufacturing of furniture, } \\
\text { clothing, eyeglass frames, cars, } \\
\text { etc. }\end{array}$ & $\begin{array}{l}\text { Trade in clothing, glasses, } \\
\text { furniture, cars, etc. }\end{array}$ \\
\hline $\begin{array}{l}\text { Creative ICT: games, new } \\
\text { media }\end{array}$ & $\begin{array}{l}\text { Creative ICT: games, new } \\
\text { media }\end{array}$ & $\begin{array}{l}\text { Trade in computers and } \\
\text { software }\end{array}$ \\
\hline $\begin{array}{l}\text { Architecture, urban design, } \\
\text { landscape architecture }\end{array}$ & $\begin{array}{l}\text { General civil and utility } \\
\text { building, project development }\end{array}$ & $\begin{array}{l}\text { Project development, trade in } \\
\text { real estate }\end{array}$ \\
\hline Advertising & Printing houses & Other advertising services \\
\hline
\end{tabular}

Note. Underlined text is part of the limited classification of the creative sector, namely creation. Bold text is part of the broad classification: creation, material production, distribution and retail. Adapted from "Creativiteit in kaart gebracht. Mapping document creatieve bedrijvigheid in Nederland" by Ministerie van Economische Zaken and Ministerie van Onderwijs, Cultuur en Wetenschap, 2005, p. 9. 


\section{Appendix B}

Codebook for the labelling and analysis of the interviews and drawings

\begin{tabular}{|c|c|}
\hline Themes & Labels \\
\hline \multirow[t]{12}{*}{ Creative Industries (CI) } & CI: Demarcation \\
\hline & CI: Culture/Museums \\
\hline & CI: Definition CI ? personal \\
\hline & CI: Definition CI ? political \\
\hline & CI: Financial interests \\
\hline & CI: Trademarks CI \\
\hline & CI: Music industry \\
\hline & CI: What industry does your organization belong to? \\
\hline & CI: Education \\
\hline & CI: Output \\
\hline & CI: Top sector/Human Capital Agenda \\
\hline & CI: Why does your organization belong to the CI? \\
\hline \multirow[t]{3}{*}{ Creativity } & Creativity: Importance of creativity \\
\hline & Creativity: Difference between creativity and creation \\
\hline & Creativity: What is creativity? \\
\hline \multirow[t]{4}{*}{ Culture } & Culture: Cultural education \\
\hline & Culture: Societal interest \\
\hline & Culture: Museums \\
\hline & Culture: What is culture to you? \\
\hline \multirow[t]{15}{*}{ Job Functions } & Functions: C_Not creative \\
\hline & Functions: C_Creative \\
\hline & Functions: F_Architect \\
\hline & Functions: F_Art/creative director \\
\hline & Functions: F_Business developer \\
\hline & Functions: F_Senior editor \\
\hline & Functions: F_Founder \\
\hline & 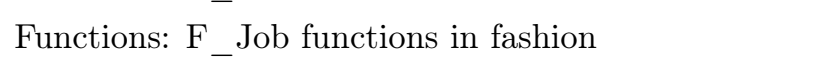 \\
\hline & Functions: F_Journalist \\
\hline & Functions: F_Junior functions \\
\hline & Functions: F_Manager \\
\hline & Functions: F_Marketing \\
\hline & Functions: F_Museums \\
\hline & Functions: F_Music industry \\
\hline & Functions: F_Designer \\
\hline
\end{tabular}




\begin{tabular}{|c|c|}
\hline Themes & Labels \\
\hline & Functions: F_Other architectural firm \\
\hline & Functions: F_Other gamedesign \\
\hline & Functions: F_Presenter \\
\hline & Functions: F_Producer \\
\hline & Functions: F_Product development \\
\hline & Functions: F_Programmer \\
\hline & Functions: F_Projectleader/Management \\
\hline & 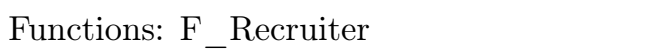 \\
\hline & Functions: F_Editorial staff \\
\hline & Functions: F_Sales \\
\hline & Functions: F_Strategist \\
\hline & Functions: KM_Necessary skills \\
\hline & Functions: KM_Creatieve job functions \\
\hline & Functions: KM_Extern/Freelance \\
\hline & Functions: KM_Flexibel deployable \\
\hline & Functions: KM_Intern/Tenure \\
\hline & Functions: KM_Internships \\
\hline & Functions: KM_Team/Cooperation \\
\hline & Functions: KM_Support \\
\hline \multirow[t]{9}{*}{ Organisation } & Organisation: Data usage \\
\hline & Organisation: Financial interests \\
\hline & Organisation: Milestones \\
\hline & Organisation: Educating \\
\hline & Organisation: Convictions/Vision \\
\hline & Organisation: Structure \\
\hline & Organisation: Changes \\
\hline & Organisation: Activities interviewee \\
\hline & Organisation: Activities organisation \\
\hline Other & Other \\
\hline \multirow[t]{8}{*}{ Process } & Process: DG_Consumer behavior \\
\hline & Process: DG_Consumer demand \\
\hline & Process: DG_Market demand \\
\hline & Process: DG_Client demand \\
\hline & Process: KM_Competition/Tender \\
\hline & Process: KM_Concept \\
\hline & Process: KM_Context \\
\hline & Process: KM_Creative intensity \\
\hline
\end{tabular}




\begin{tabular}{|c|c|}
\hline Themes & Labels \\
\hline & Process: KM_Diverging/Converging \\
\hline & Process: KM_Innovation \\
\hline & Process: KM_Iterations \\
\hline & Process: KM_Trademarks \\
\hline & Process: KM_Linear \\
\hline & Process: KM_Motive \\
\hline & Process: KM_Problemanalysis output \\
\hline & Process: KM_Working by means of a process \\
\hline & Process: KM_Differences \\
\hline & Process: KM_Different ways of thinking \\
\hline & Process: KM_Vision \\
\hline & Process: KM_Waterfall method \\
\hline & Process: MW_Agile/scrum \\
\hline & Process: MW_Briefing/Meeting \\
\hline & Process: MW_Content creation and management \\
\hline & Process: MW_Game design \\
\hline & Process: MW_Inspirations \\
\hline & Process: MW_Design process \\
\hline & Process: MW_Parallel activities \\
\hline & Process: MW_What is the creative process? \\
\hline & Process: ST_Assemble (external) team \\
\hline & Process: ST_(Problem)analysis \\
\hline & Process: ST_Final design \\
\hline & Process: $\mathrm{ST}_{\text {Introduction }}$ \\
\hline & Process: $\mathrm{ST}_{\text {_Design phases }}$ \\
\hline & Process: ST_Parametrisation \\
\hline & Process: ST_Presentation \\
\hline & Process: ST_Prototype/Testing \\
\hline & Process: ST_Reflection \\
\hline & Process: ST_Sketching \\
\hline & Process: ST_Strategy defenition \\
\hline & Process: ST_Technical design \\
\hline & Process: ST_Mid-term analysis \\
\hline & Process: ST_Execution/Production \\
\hline & Process: ST_Preliminary design \\
\hline \multirow[t]{2}{*}{ Process Steps (PS) } & PS: Step 1 \\
\hline & PS: Step 2 \\
\hline
\end{tabular}




\begin{tabular}{|c|c|}
\hline \multirow[t]{4}{*}{ Themes } & Labels \\
\hline & PS: Step 3 \\
\hline & PS: Step 4 \\
\hline & PS: Step 5 \\
\hline \multirow[t]{27}{*}{ Skills } & Skills: Context_Cultural awareness \\
\hline & Skills: Context_Ethical awareness \\
\hline & Skills: Context_Flexibility \\
\hline & Skills: Context_Lifelong learning \\
\hline & Skills: Context_Self-direction \\
\hline & Skills: Core_Collaboration \\
\hline & Skills: Core_Communication \\
\hline & Skills: Core_Creativity \\
\hline & Skills: Core_Critical thinking \\
\hline & Skills: Core_Information management \\
\hline & Skills: Core_Problem-solving \\
\hline & Skills: Core_Technical \\
\hline & Skills: Digital skill \\
\hline & Skills: General_21st century skills \\
\hline & Skills: General_Function aspecific \\
\hline & Skills: General_Function specific \\
\hline & Skills: I_Analytic ability \\
\hline & Skills: I_Broadly oriented \\
\hline & Skills: I_Empathy \\
\hline & Skills: I_Higher priority \\
\hline & Skills: I_Initiative \\
\hline & Skills: I_Lower priority \\
\hline & Skills: I_Curious \\
\hline & Skills: I_Broad-minded \\
\hline & Skills: I_Tenacity \\
\hline & Skills: I_Business sense \\
\hline & Skills: Interviewee \\
\hline
\end{tabular}




\section{Biographies}

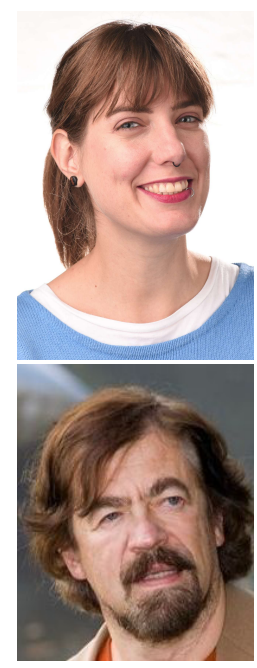

Mirjam M. Koehorst. After graduating cum laude for her master Educational Science and Technology at the University of Twente, Mirjam started her PhD at the department of Communication Science early 2016. Her research is about organizational factors that influence the level of 21st-century digital skills of employees in the creative industries in the Netherlands.

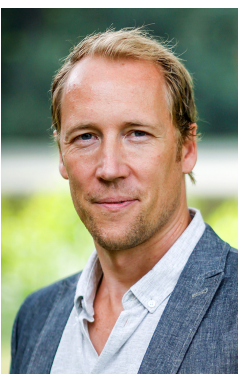

Jan A.G.M. van Dijk. Emeritus professor of Communication Science and the Sociology of the Information Society. Important books: 'The Network Society', 'Internet Democracy in the Network Society', 'The Deepening Divide', 'The Digital Divide', 'Digital Skills' and 'ICT in Organizations'

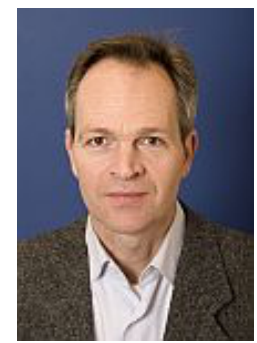

Alexander J.A.M. van Deursen. Prof. dr. Alexander JAM van Deursen is chair of the Communication Science Department at the University of Twente. Most of his research focuses on digital inequality in contemporary society. Research projects he is involved in concern annual trends in Internet use, digital inequality in internet-of-things skills, 21st century digital skills at work, and measurements of skills, engagement and outcomes of Internet (ofthings) use. He wrote numerous articles on digital inequality and in 2014 published the book 'Digital Skills, Unlocking the Information Society.' Alexander collaborates with civic organizations to improve service provision and policy making at the national and international level.

Jos De Haan. Jos de Haan works as a senior researcher at the Netherlands Institute of Social Research (SCP) His research focuses on media use and the diffusion and use of ICTs. 